TITLE:

\title{
$<$ Notes> Predation on a Monkey by Savanna Chimpanzees at Fongoli, Senegal
}

\author{
$\operatorname{AUTHOR}(\mathrm{S}):$
}

Gaperi, M.; Pruetz, J.D.

\section{CITATION:}

Gaperi, M....[et al]. < Notes> Predation on a Monkey by Savanna Chimpanzees at Fongoli, Senegal. Pan Africa News 2004, 11(2): 8-10

ISSUE DATE:

2004-12

URL:

http://hdl.handle.net/2433/143443

RIGHT:

Copyright (C) Pan Africa News. 
<NOTES>

Predation on a monkey by savanna chimpanzees at Fongoli, Senegal

M. Gašperšič and J.D. Pruetz Institutum Studiorum Humanitatis (ISH), Ljubljana, Slovenija and Iowa State University, Department of Anthropology, Ames, Iowa Although forest-living chimpanzees commonly include vertebrate prey such as monkeys in their diet ${ }^{1}$, savanna chimpanzees have been reported only to eat prosimians ${ }^{2}$. New evidence from the recently-established Fongoli study site in Senegal suggests that chimpanzees there hunt green monkeys (Cercopithecus aethiops sabeus). The Fongoli community ranges over an area of at least $63 \mathrm{~km}^{2}$ and based on fecal analyses, consumes a species of bushbaby found here probably Galago senegalensis. In the third year of study of the Fongoli community, researchers recorded the following:

On 8 June, 2004, MG and a Senegalese field assistant, Mbouli Camara, searched an area on the left bank of the Fongoli stream, a tributary of the Gambia River in southeastern Senegal, for signs of chimpanzees. At $7 \mathrm{~h} 13$ we heard pant hoots about $400 \mathrm{~m}$ away and about $1 \mathrm{~km} \mathrm{E}$ from the village of Fongoli. We followed the calls toward the Gambia River, which at that time was the only available water source apart from a small spring near the village of Djendji, several $\mathrm{km}$ away. At $7 \mathrm{~h} 23$ we found a party of chimpanzees along the empty riverbed of the smaller $\mathrm{Fa}-\mathrm{Fa}$ tributary. The party was moving away, about 30-35 $\mathrm{m}$ from us, on the ground in bamboo woodland. Researchers identified 'Mamadou', a young adult male of the community, a second adult male, a female with an infant, and 3 other 
immature chimpanzees. We saw 7 chimpanzees on the ground, but heard more pant-hoots from the surrounding dense vegetation. The three immature individuals and both males vocalized and moved in circles around an object on the ground, which was not recognizable from a distance. The observed behavior involved agonistic chasing, as interpreted by JDP after viewing video footage of the event. After 3 minutes the chimpanzees noticed the observers and retreated to the nearby woodland, emitting soft pant-hoots. We waited for 10 minutes and then approached the site along the dry streambed. There we found a dead green monkey, apparently a young female. The skull was completely fractured in the frontal, parietal, and occipital regions, exhibiting a radiating fracture pattern indicative of blunt force trauma. The pattern of fracture suggests that the monkey was killed by hitting its head against a hard substrate, as has been observed at Tai Forest ${ }^{3}$. The brain was partly missing, and the blood was fresh and not yet dried. The monkey had wounds on the neck and shoulders; the left leg had no flesh left on it; both right limbs were missing, apparently having been pulled off. The abdominal area was ripped open, with intestines spilling out. The victim appeared freshly killed, as there eas no odor of decay; there was no maggot activity, and few flies had arrived at the corpse. We waited nearby for 30 minutes, in case the chimpanzee party came back, but they did not. We returned to the spot the next day to examine the body, but it was gone. MG filmed the encounter, but the actual hunt or kill and the monkey cannot be seen due to the distance and dense vegetation. Given the evidence, both behavioral and physical, we conclude that this is the first evidence of monkey hunting by savanna chimpanzees of west Africa. Primate prey species commonly hunted by chimpanzees at other sites, such as colobus monkeys, do not occur in this semiarid environment (Guinean and Sudo-Guinean vegetation types). We suspect that vertebrate hunting by Fongoli chimpanzees is opportunistic and probably not cooperative, as the prey species is the most terrestrial African guenon. Other potential chimpanzee prey species that occur at Fongoli include the patas monkey (Erythrocebus patas) and Guinea baboons (Papio papio), as well as smaller ungulates such as bush duiker (Cephalophus sp.), oribi (Ourebia ourebi), warthog (Phacochoerus aethiopicus), and bushbuck (Tragelaphus scriptus). Encounters between patas monkeys and chimpanzees have not yet been observed. Agonistic encounters between chimpanzees and baboons have been observed during the peak of the dry season when both species are drawn to a few available water sources in the study area. Contest competition between chimpanzees and baboons over water has been recorded, with chimpanzees acting as aggressor but baboons retaliating in large groups; baboons acting as aggressor, with chimpanzees retreating; and, at other times, chimpanzees and baboons drink sequentially at the water source, with no overt competition. Baboons have also been observed to avoid the approach of chimpanzees as signalled by pant-hooting.

With increased habituation of the Fongoli community, we hope to clarify the hunting behavior of chimpanzees in such an open habitat as well as patterns of meat sharing and other related behaviors.

We acknowledge funding by the U.S. Fish and Wildlife Great Ape Conservation fund, permission to work in Senegal granted by the Eaux et Forets du Senegal and the Republique du Senegal, and field assistance by Mbouli Camara and Dondo Kante.

\section{References}

1. Stanford C 1998. Chimpanzee and Red Colobus: The Ecology of Predator and Prey. Harvard University Press, Cambridge.

2. McGrew WC., Baldwin PJ, and Tutin CEG. 1988. Diet of wild chimpanzees (Pan troglodytes verus) at Mt. Assirik, Senegal. I. Composition. Amer J Primatol 16:213-226. 
3. B o e s ch C, B o e s ch-A chermann H 2000. The Chimpanzees of the Taï Forest. Oxford University Press, Oxford. 